\title{
DIE TAT-Z AS VOORSPELLER VIR PRESTASIEMOTIVERING
}

\author{
F.V.N. CILLIERS \\ M.P. WISSING \\ DEPARTEMENT BEDRYF. EN PERSONEELSIELKUNDE \\ POTCHEFSTROOMSE UNIVERSITEIT VIR C.H.O.
}

\begin{abstract}
SUMMARY
The TAT-Z, a projection test for Black males, is investigated for predicting achievement motivation in the employment situation. Positive results are reported on 3 of the 10 cards (nos. 4, 6 and 9) of the TAT-Z. Recommendations are made for improving the TAT-Z to provide more information on achievement motivation.
\end{abstract}

In die bedryfsituasie is dit van ekonomiese belang om werkers wat hulle "bes doen" in diens te hê, of in diens te neem, dit wil sê werkers wat kan presteer. Aangesien prestasie self sterk situasiegebonde is, is die voorspelling daarvan problematies. Uit die literatuur blyk dit dat daar verband tussen prestasie en prestasiemotivering bestaan. Laasgenoemde, wat 'n meer algemene persoonlikheidseienskap is, kan dus gebruik word as voorspeller van verwagte prestasie. Verskeie tegnieke, waaronder die Tematiese Appersepsietoets (TAT) is al in die verlede gebruik om prestasiemotivering by verskillende groepe te evalueer (McClelland, 1961).

Sover bekend is daar nog nie ondersoeke na prestasiemotivering by die Swartman in Suid-Afrika gedoen nie. In ons ekonomiese situasie vorm die Swartman 'n groot deel van die mannekragpotensiaal, wat dit noodsaaklik maak om in keuring ook sy vlak van prestasiemotivering te probeer peil, en wel met behulp van toetse wat spesiaal vir die doel gestandaardiseer is.

Die doel van hierdie ondersoek was om vas te stel of die Tematiese AppersepsietoetsZoeloe (TAT-Z), 'n projektiewe tegniek wat spesiaal deur die RGN vir die Swartman gekonstrueer is, kan dien tot die peiling van prestasiemotivering by die Swartman.

Meer spesifiek gestel, is die volgende beoog:

- $\quad$ om die geskiktheid van die TAT-Z vir die meting van prestasiemotivering te bepaal 
- $\quad$ om aan te toon watter van die tien kaarte van hierdie projeksietoets daarin slaag om prestasiemotivering die duidelikste na vore te bring

- $\quad$ om na te gaan of daar 'n verband bestaan tussen realiteitsbelewing (soos gemeet deur die TAT-Z) en prestasiemotivering (soos gemeet deur 'n vraelys wat vir hierdie doel saamgestel is) en

- $\quad$ om na te gaan of daar 'n verband bestaan tussen verwestering by die Swartman (soos gemeet deur die TAT-Z) en prestasiemotivering.

Die behoefte aan prestasie is een van die mens se sosiale motiewe. Uit hierdie motief ontstaan gemotiveerdheid om te presteer (McClelland, 1977). Hierdie eienskap is by alle mense in ' $\mathrm{n}$ mindere of meerdere mate teenwoordig (Barnard, 1971).

Prestasiemotivering het te doen met die konsep van effektiwiteit, veral gesien vanaf die kant van die werkgewer. Die grondslag hiervan word gevorm deur die houding van "as ek die werk meer effektief kan doen, sonder om myself te ooreis, het ek myself verbeter" (McClelland, 1977, p.15). Van die kant van die werknemer gesien kan prestasiemotivering verskillende onderliggende bronne hê, soos die behoefte aan waardering, erkenning of mag, of as kompensering vir minderwaardigheidsgevoelens.

Prestasiemotivering kan verder omskryf word as die mens se strewe om sy eie bekwaamheid te verhoog, of so hoog moontlik te hou in alle aktiwiteite waarin daar 'n standaard van uitsonderlikheid ter sprake is, en waar die uitvoering van sulke aktiwiteite kan slaag of misluk (na aanleiding van Heckhausen, 1957). Aan die een kant poog die persoon om mislukking te vermy (Deci, 1975 in Van der Merwe, 1976), en aan die ander kant beleef hy 'n sterker motief, of intrinsieke motivering om suksesvol te wees. Hierdeur bereik hy 'n gevoel van bekwaamheid (McClelland, 1963 in Van der Merwe, 1976), en 'n hoë standaard van doeltreffendheid.

Die vraelysmetode en projektiewe tegnieke word redelik algemeen gebruik vir die meting van prestasiemotivering. Die groot voordeel van die vraelys is die verskeidenheid individuele verskille wat blootgelê kan word (Fullard, 1969; Costello, 1967). Verder gee die vraelys ' $n$ relatief betroubare weergawe van die eienskappe van die proefpersoon in 'n kort tydsbestek.

Van die verskillende metodes van vraelyssamestelling, het die Likert-metode die meeste voordele. Die skaal is eenvoudig om op te stel, en die reeks response gee meer presiese inligting oor die individu se houdinge of motiewe. Dié metode met sy vyf 
responsalternatiewe is meer betroubaar as die Thurstone-metode (Jahada en Warren, 1966) met dieselfde aantal items. Die betroubaarheid van 'n Likert-skaal is gewoonlik in die omgewing van 0,85 (Oppenheim, 1968), wat deels toegeskryf kan word aan die groter reeks response wat toegelaat word.

Die projektiewe tegniek is die metode wat die meeste gebruik word in die meting van prestasiemotivering (Atkinson en Feather, 1966; Costello, 1967), moontlik omdat die tegniek die gevoeligste is vir prestasiemotivering (Van der Merwe, 1976).

Daar bestaan gewoonlik 'n klein, maar positiewe korrelasie tussen die projektiewe tegniek en die vraelys in die meting van prestasiemotivering. Die rede hiervoor kan moontlik lê in die feit dat die twee tegnieke so wesentlik van mekaar verskil - hulle vul mekaar eintlik aan (Allport, in McClelland, 1961; Van der Merwe, 1976). Daar word waarskynlik verskillende komponente van motivering gemeet, en gevolglik verskillende komponente van die variasie van gedrag (Sherwood, 1966).

Die projektiewe tegniek wat die geskikste is vir die meting van prestasiemotivering, is die tematiese appersepsietipe toets, omdat die toets neig om die "fantasie los te maak". Die navorsing van McClelland is van groot waarde hierin. Hieruit het geblyk dat prestasiemotivering voorspel kan word op grond van response op TAT-kaarte.

Die Tematiese Appersepsietoets-Zoeloe is in 1976 opgestel deur die Instituut vir Psigometriese Navorsing van die Raad vir Geesteswetenskaplike Navorsing. Die toets kan op alle Swartmans bokant die ouderdom van sestien jaar in Suid-Afrika toegepas word.

In die kliniese konteks is die TAT-Z van besondere waarde vir individuele toetsing, maar die toets bied ook vele moontlikhede vir die bedryfsielkundige waar die toets in sy gestruktureerde vorm in groepe afgeneem kan word, met die oog op bemanningsaktiwiteite. In die response kom die hantering van basiese interpersoonlike situasies en -verhoudinge, persoonlikheidseienskappe en houdinge tot uiting, wat tot die voorspelling van optrede in bedryfsituasies kan dien.

Die TAT-Z is ' $n$ aanpassing van die TAT van Murray. Om 'n Tematiese Appersepsietoets vir Swartmans daar te stel, moes daar egter sekere aanpassings gemaak word. Uit die studies van Erasmus (1971) oor die persoonlikheid van die Swartman, het geblyk dat die Swartman in Suid-Afrika homself in 'n akkulturasieproses bevind wat gekenmerk word deur elemente van tradisionalisme aan die een kant, en verwestering aan die ander kant, met wisselende norme en waardes tussen die twee pole. As oplossing hiervoor is besluit op die 
insluit van keusekaarte. By agt van die tien persoonlikheidsdimensies wat gemeet word, moet die proefpersoon 'n keuse maak tussen 'n westerse en 'n tradisionele situasie op die kaart. Hierdie situasie word in kleur uitgebeeld om die realiteit daarvan te verhoog.

Wanneer die toets in groepsverband afgeneem word, beantwoord die proefpersoon spesifieke en gestruktureerde vrae in 'n antwoordboek. Die afneem van die toets duur ongeveer een tot een-en-'n-half uur, afhangende van die persoon se opvoedkundige peil. Die TAT-Z word volgens 'n standaardnasiensleutel geïnterpreteer.

Ten spyte van die feit dat die TAT-Z 'n projektiewe tegniek is, besit die toets 'n hoë mate van geldigheid en betroubaarheid. Hierdie feit blyk uit konstrukgeldigheidstudies wat deur Minnaar (1975) onderneem is. In die laasgenoemde studie is twee groepe Swartmans betrek, en die resultate soos in Tabel 1 aangedui, is verkry:

\section{$\underline{\text { TABEL } 1}$}

TOETS-HERTOETS BETROUBAARHEID VAN DIE TAT-Z

\begin{tabular}{|c|c|c|c|}
\hline GROEP & $\mathrm{N}$ & TYDVERLOOP & $\mathrm{r}$ \\
\hline 1 & 18 & 14 dae & 0,887 \\
2 & 32 & 7 maande & 0,753 \\
\hline
\end{tabular}

Teen die agtergrond van die voorafgaande en ten einde die doelstellings van die studie te bereik, soos ten aanvang uiteengesit, is die volgende hipoteses reformuleer:

Daar bestaan geen verband tussen prestasiemotivering, en die volgende tellings op die TAT-Z nie:

Totale TAT-Z-telling (HO)

- Kaart $1(\mathrm{H} 1)$,

- Kaart 2 (H2),

- Kaart $3(\mathrm{H} 3)$,

- Kaart 4 (H4),

- Kaart 5 (H5),

- Kaart 6 (H6),

- Kaart 7 (H7),

- Kaart 8 (H8),

- Kaart 9 (H9), 
- Kaart 10 (H10),

Realiteitsbelewing (H11),

Verwestering (H12).

\section{METODE}

Ses-en-veertig stedelike en plattelandse Swartmans, tussen die ouderdom van 20 en 40, met opvoedkundige kwalifikasies tussen standerd 6 en 10, is in die ondersoek ingesluit. (Die Tematiese Appersepsie-Zoeloe het nie slegs op Zoeloes betrekking nie, maar kan op alle Swartgroepe in Suid-Afrika gebruik word.)

Verder was al die proefpersone meer as twaalf maande werksaam by die maatskappy wat in die ondersoek betrek is, naamlik 'n pypvervaardigingsbedryf met sy hoofkantoor in die Vaaldriehoek. Die proefpersone was beperk tot klerke en stoormanne in die handelsafdelings in drie streke, naamlik Transvaal (Johannesburg, Pretoria, Nelspruit, Pietersburg en Klerksdorp), die Vrystaat (Bloemfontein en Welkom) en die Noord-Kaapprovinsie (Kimberley).

\section{Die meetmiddels}

\section{Die TAT-Z}

Die TAT-Z is in groepe van vyf tot sewe afgeneem. In die interpretasie van die response is gebruik gemaak van die standaardnasiensleutel, waaruit die volgende gegewens vir elke toetspersoon verkry is : ' $n$ Totale telling uit 100, wat bestaan uit ' $n$ telling op elkeen van die tien kaarte, 'n telling vir realiteitsbelewing, en 'n telling vir verwestering. Laasgenoemde is gebaseer op die persoon se keuses tussen westerse en tradisionele kaarte.

\section{Die vraelys}

Omdat daar geen vraelys vir die meting van prestasiemotivering by Swartes in SuidAfrika bestaan nie, is die prestasie-motiveringsvraelys opgestel (kyk bylaag) wat meet volgens die Likert-metode. Die vraelys is gegrond op faktore wat volgens die literatuur 'n rol speel in prestasiemotivering (Pottas, 1969; Van der Merwe, 1976; Fullard, 1969; Coertze, 1974; Orpen, 1976; Weiner, 1974; McClelland en Winter, 1969; Rim, 1963). Hierdie faktore word uiteengesit in Tabel 2, en kan gedeel word in persoonlikheidseienskappe, en eienskappe in die werk self. 'n Positief (+) dui daarop dat die faktor prestasiemotivering verhoog, en 'n negatief (-) dat prestasiemotivering verhinder word. 


\section{TABEL 2}

\section{EIENSKAPPE WAT 'N ROL SPEEL IN PRESTASIEMOTIVERING}

\begin{tabular}{|ll|ll|}
\hline & PERSOONLIKHEIDSEIENSKAPPE & EIENSKAPPE IN DIE WERK \\
\hline 1 & aanpassing (+) & 22 & hulp van ander ontvang (-) \\
2 & bekwaamheid (+) & 23 & groepsuitlewing (+) \\
3 & aggressie (+) & 24 & getrouheid (+) \\
4 & intelligensie (+) & 25 & kwaliteit van werk (+) \\
5 & dagdromery (-) & 26 & tyd en deeglikheid (+) \\
6 & vermoë (+) & 27 & kennis en opleiding (+) \\
7 & gemotiveerdheid (+) & 28 & samewerking (+) \\
8 & deur groepsopinie beïnvloed (-) & 29 & terugvoering (+) \\
9 & belangstelling (+) & 30 & verantwoordelikheid (+) \\
10 & hulpvaardigheid (+) & 31 & behoefte aan prestasie (-) \\
11 & behoefte aan sukses (+) & 32 & ongeluksgeneigdheid (-) \\
12 & soeke na status (-) & 33 & kwaliteit van werk (+) \\
13 & entoesiasme (1) & 34 & konsentrasie (-) \\
14 & sedelike standaard (+) & 35 & tydsuitbuiting (+) \\
\hline
\end{tabular}

\section{TABEL 2 (VERVOLG)}

\begin{tabular}{|c|c|}
\hline 15 goeie selfbeeld (+) & 36 stiptheid (+) \\
\hline 16 doelgerigdheid (+) & 37 roetinetake $(-)$ \\
\hline 17 beïnvloedbaarheid (-) & 38 konsentrasie $(+)$ \\
\hline 18 geestesgesondheid (+) & 39 respekbetoning $(-)$ \\
\hline 19 mislukking-geneidgheid (-) & 40 uithouvermoë (+) \\
\hline 20 samewerking met groepslede (+) & \\
\hline 21 gekantheid teen verandering $(+)$ & \\
\hline
\end{tabular}

'n Vraelys waarin die proefpersoon homself beoordeel ten opsigte van prestasiemotivering, kon nie gebruik word nie vanweë die praktiese probleme verbonde aan die oordra van die begrippe in die vraelys aan die Swartman. Navorsing van Appley (uit Barnard, 1971) het verder aangetoon dat direkte vrae wat aan die proefpersoon gestel word, nie geskik is vir die meting van prestasiemotivering nie (Barnard, 1971). Studies van Lowell (1950) asook Linsey en Heineman (1955, in Sherwood, 1966), Van der Merwe,(1976), Hermans (1967) en McClelland, (1961) het die verband tussen direkte navraag en TAT-tegnieke in die bepaling van prestasiemotivering ondersoek. Die korrelasies wat verkry is, is swak en strek vanaf 0,23 tot $-0,45$ (Sherwood, 1966). Gevolglik is die vraelys deur elke persoon se onmiddellike Blanke toesighouer voltooi. 
Die vraelys is soos volg nagesien:

- $\quad$ by die vrae wat positiewe eienskappe van prestasiemotivering meet, tel 'n SSS-respons vyf punte en 'n VS-respons een punt;

- $\quad$ by die vrae wat negatiewe eienskappe van prestasiemotivering meet, is die puntetoekenning andersom, een punt vir 'n SSS-respons en vyf punte vir 'n VS-respons.

Die vraelysgegewens is aan 'n paneel van deskundiges voorgelê, wat tot die slotsom gekom het dat die vraelys inhoudsgeldigheid besit.

Vervolgens is t-waardes uitgewerk, en nege faktore met t-waardes kleiner as 2,0168, en 'n korrelasie van 0,3 en kleiner op die $5 \%$ waarskynlikheidsvlak, is uit die vraelys gehaal. Hierdie faktore word in die vraelys gedek deur vrae 3, 8, 12, 15, 16, 21, 26, 29 en 37 . In 'n faktorontleding wat op die totale vraelys uitgevoer is, het hierdie nege faktore weer eens die laagste eie-waardes behaal. Daar is dus aanvaar dat die faktore nie duidelik diskrimineer nie, en gevolglik is hulle uit die vraelys gehaal.

'n Telling vir prestasiegemotiveerdheid is vir elke proefpersoon bereken deur die waardes van die oorblywende 31 faktore bymekaar te tel.

\section{Korrelasies tussen die TAT-Z-tellings en die prestasiemotiveringsvraelys}

Uit die gegewens in Tabel 3 volg dat beduidende korrelasies gevind is op kaart 4, kaart 6 en kaart 9.

Hipoteses 4, 6 en 9 word dus verwerp, omdat daar 'n beduidende verband bestaan tussen die telling behaal op die prestasiemotiveringsvraelys, en die tellings behaal op kaarte 4 , 6 en 9 van die TAT-Z. 


\section{TABEL 3}

\section{BEDUIDENDHEID VAN KORRELASIES TUSSEN TAT-Z-TELLINGS EN PRESTASIEMOTIVERINGSVRAELYSTELLINGS}

\begin{tabular}{|c|c|c|c|c|}
\hline HIPOTESE & $\begin{array}{c}\text { TAT-Z- } \\
\text { TELLING }\end{array}$ & $\mathrm{r}$ & t-WAARDE & $\begin{array}{l}\text { HIPOTESE } \\
\text { VERWERP }\end{array}$ \\
\hline $\mathrm{HO}$ & totaal & 0,27355 & 1,8879 & nee \\
\hline $\mathrm{H} 1$ & kaart 1 & $-0,1822$ & 1,2286 & nee \\
\hline $\mathrm{H} 2$ & kaart 2 & 0,06004 & 0,3995 & nee \\
\hline $\mathrm{H} 3$ & kaart 3 & 0,11879 & 0,7935 & nee \\
\hline $\mathrm{H} 4$ & kaart 4 & $0,31618^{*}$ & 2,2080 & ja \\
\hline H5 & kaart 5 & 0,11058 & 0,7372 & nee \\
\hline H6 & kaart 6 & $0,34953 *$ & 2,4719 & ja \\
\hline $\mathrm{H} 7$ & kaart 7 & 0,19492 & 1,317 & nee \\
\hline H8 & kaart 8 & 0,11981 & 0,8003 & nee \\
\hline H9 & kaart 9 & $0,32956 *$ & 2,3127 & ja \\
\hline $\mathrm{H} 10$ & kaart 10 & 0,09640 & 0,6427 & nee \\
\hline H11 & realisme & 0,14640 & 0,9826 & nee \\
\hline $\mathrm{H} 12$ & verwestering & 0,05771 & 0,3829 & nee \\
\hline
\end{tabular}

\section{Die totale TAT-Z-telling}

Hierdie telling toon 'n beduidende korrelasie met die prestasiemotiveringsvraelys. Die totale TAT-Z-telling, uitgedruk in 'n persentasie, waarin die huidige nasiensleutel en gewigstoekenning gebruik word, kan dus nie as maatstaf dien vir die meting van prestasiemotivering nie, as aangeneem word dat die vraelys 'n geldige instrument vir die meting van prestasiemotivering is .

\section{Afsonderlike TAT-Z-telling}

Soos aangedui, bestaan daar beduidende korrelasies tussen die prestasiemotiveringsvraelys, en sommige kaarte van die TAT-Z, naamlik kaarte 4, 6 en 9.

Kaart 6, die Blanke gesagskaart, toon die sterkste verband met die vraelys, naamlik $r=0,31618$. Daar kan dus verwag word dat die proefpersoon se verhaal oor die interaksie met die Blanke op die kaart, response sal ontlok met 'n sterk prestasiemotiveringsinhoud. As verklaring hiervoor kan moontlik aangevoer word dat die proefpersoon in die kaart iets lees van die werker-werknemerverhouding. Die proefpersoon kan hierdie kaart dus met betrekking tot 'n werksituasie interpreteer. 
Die tweede grootste verband is verkry tussen die prestasiemotiveringsvraelys en kaart 9 van die TAT-Z ( $r=0,32956)$, die groepsidentifikasie-kaart. Hier kan verwag word dat die proefpersoon sal identifiseer met die individu wat alleen op die kaart staan, en dat hieruit prestasiemotiveringsresponse sal vloei.

Die derde grootste beduidende verband is verkry tussen die prestasiemotiveringsvraelys en kaart 4 van die TAT-Z, die moeder-seun-kaart.

Op kaart 1 van die TAT-Z, die akkulturasiekaart, waarby prestasiemotiveringsresponse verwag sou word uit die aard van die stimulusinhoud, is 'n onbeduidende maar positiewe korrelasie met die prestasiemotiveringsvraelys verkry.

\section{Realiteitsbelewing}

'n Onbeduidende verband is verkry tussen die tellings vir realiteitsbelewing (soos gemeet deur die TAT-Z) en die prestasiemotiveringsvraelys.

\section{Verwestering}

Daar bestaan ook 'n onbeduidende verband tussen verwestering (soos gemeet deur die TAT-Z) en die vraelys oor prestasiemotivering.

\section{GEVOLGTREKKINGS}

Soos blyk uit die voorafgaande bestaan daar 'n swak, maar positief-beduidende verband tussen drie kaarte (4, 6 en 9) van die TAT-Z, en die prestasiemotiveringsvraelys. Op sigself is dit belowende resultate.

Die gevoel bestaan egter dat die gebruik van die TAT-Z in die meting van prestasiemotivering verhoog behoort te word. Dit kan moontlik bereik word deur kaarte in te sluit wat 'n spesifieke werksituasie uitbeeld, of deur in die huidige nasiensleutel gewigte toe te ken aan prestasiemotiveringsresponse. 
Bylaag

VRAELYS OOR PRESTASIEMOTIVERING BY SWARTWERKNEMERS

NAAM

TOESIGHOUER

DIE INLIGTING OP HIERDIE VRAELYS WORD SLEGS VIR NAVORSING GEBRUIK, EN NIE OM ENIGE PERSOON TE BEVOORDEEL OF TE BENADEEL NIE.

Die doel van die vrae is om te meet hoe goed die Swartman gemotiveerd is om te presteer. U moet dus elke vraag op hom van toepassing maak. Beantwoord asseblief al die vrae so eerlik as moontlik. Ons beskou die antwoorde as vertroulik, en u moet dit ook asseblief met niemand bespreek nie.

By elke vraag kan u uit 5 moontlike antwoorde kies. 'n Stelling word gemaak, en u moet 'n keuse uit die volgende maak:

$\mathrm{SSS}=$ stem sterk saam

$\mathrm{SS}=$ stem saam

$\mathrm{O}=$ onseker

$\mathrm{V}=$ verskil

$\mathrm{VS}=$ verskil sterk

Trek telkens 'n kruis oor die antwoord wat u dink by die Swartman pas. 


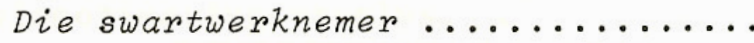

1 pas homself goed aan by sy medewerkers

$\begin{array}{lllll}\text { SSS } & \text { SS } & 0 & \text { V } & \text { VS }\end{array}$

2 is goed genoeg vir sy werk

$\begin{array}{lllll}\text { SSS } & \text { SS } & 0 & \text { V }\end{array}$

3 raak gou kwaad

$\begin{array}{lllll}\text { SSS } & \text { SS } & 0 & \text { V } & \text { VS }\end{array}$

4 leer iets vinnig aan

$\begin{array}{lllll}\text { SSS } & \text { SS } & 0 & \text { V } & \text { VS }\end{array}$

5 bestee baie tyd aan dagdromery

$\begin{array}{lllll}\text { SSS } & \text { SS } & 0 & \text { V } & \text { VS }\end{array}$

6 doen sy werk soos dit van hom verwag word

$\begin{array}{lllll}\text { SSS } & \text { SS } & 0 & \text { V } & \text { VS }\end{array}$

7 is gemotiveerd om hard te werk

$\begin{array}{lllll}\text { SSS } & \text { SS } & 0 & \text { V } & \text { VS }\end{array}$

8 gee om oor wat sy werksgroep van hom dink

$\begin{array}{lllll}\text { SSS } & \text { SS } & 0 & \mathrm{~V} & \text { VS }\end{array}$

9 verloor gou belangstelling in sy werk

$\begin{array}{lllll}\text { SSS } & \text { SS } & 0 & \text { V }\end{array}$

10 gee graag hulp aan ander

$\begin{array}{lllll}\text { SSS } & \text { SS } & 0 & \text { V } & \text { VS }\end{array}$

11 wil graag sukses behaal

$\begin{array}{lllll}\text { SSS } & \text { SS } & 0 & \text { V } & \text { VS }\end{array}$

12 is bewus van sy status

$\begin{array}{lllll}\text { SSS } & \text { SS } & 0 & \text { V } & \text { VS }\end{array}$

13 werk fluks en hard as 'n nuwe stuk werk aan hom gegee word $\begin{array}{lllll}\text { SSS } & \text { SS } & 0 & \text { V } & \text { VS }\end{array}$

14 vloek en gedra homself swak

$\begin{array}{lllll}\text { SSS } & \text { SS } & 0 & \text { V } & \text { VS }\end{array}$


15 onderskat homself

$\begin{array}{lllll}\text { SSS } & \text { SS } & 0 & \mathrm{~V} & \text { VS }\end{array}$

16 werk eerder alleen as met ander mense rondom hom $\begin{array}{llllll}\text { SSS } & \text { SS } & 0 & \text { V } & \text { VS }\end{array}$

17 word maklik deur die groep beĩnvloed

$\begin{array}{lllll}\text { SSS } & \text { SS } & 0 & \text { V } & \text { VS }\end{array}$

18 tree altyd normaal op

$\begin{array}{llllll}\text { SSS } & \text { SS } & 0 & \text { V } & \text { VS }\end{array}$

19 probeer om altyd te slaag in dit wat hy doen

$\begin{array}{lllll}\text { SSS } & \text { SS } & 0 & \mathrm{~V} & \text { VS }\end{array}$

20 kom goed klaar met die mense wat saam met hom werk

$\begin{array}{lllll}\text { SSS } & \text { SS } & 0 & \text { V } & \text { VS }\end{array}$

21 hou nie van verandering nie

$\begin{array}{llllll}\text { SSS } & \text { SS } & 0 & \text { V } & \text { VS }\end{array}$

22 kry baie hulp nodig van ander

$\begin{array}{lllll}\text { SSS } & \text { SS } & 0 & \text { V } & \text { VS }\end{array}$

23 hou van sy werk en die mense wat saam met hom werk $\begin{array}{lllll}\text { SSS } & \text { SS } & 0 & \text { V } & \text { VS }\end{array}$

24 is baie afwesig van die werk

$\begin{array}{llllll}\text { SSS } & \text { SS } & 0 & \text { V } & \text { VS }\end{array}$

25 lewer goeie werk

$\begin{array}{llllll}\text { SSS } & \text { SS } & 0 & \text { V } & \text { VS }\end{array}$

26 werk stadig maar deeglik

$\begin{array}{lllll}\text { SSS } & \text { SS } & 0 & \text { V }\end{array}$

27 het genoeg kennis om 'n sukses te makk $\begin{array}{lllll}\text { SSS } & \text { SS } & 0 & \mathrm{~V} & \text { VS }\end{array}$

28 gee sy volle samewerking

$\begin{array}{lllll}\text { SSS } & \text { SS } & 0 & \text { V } & \text { VS }\end{array}$




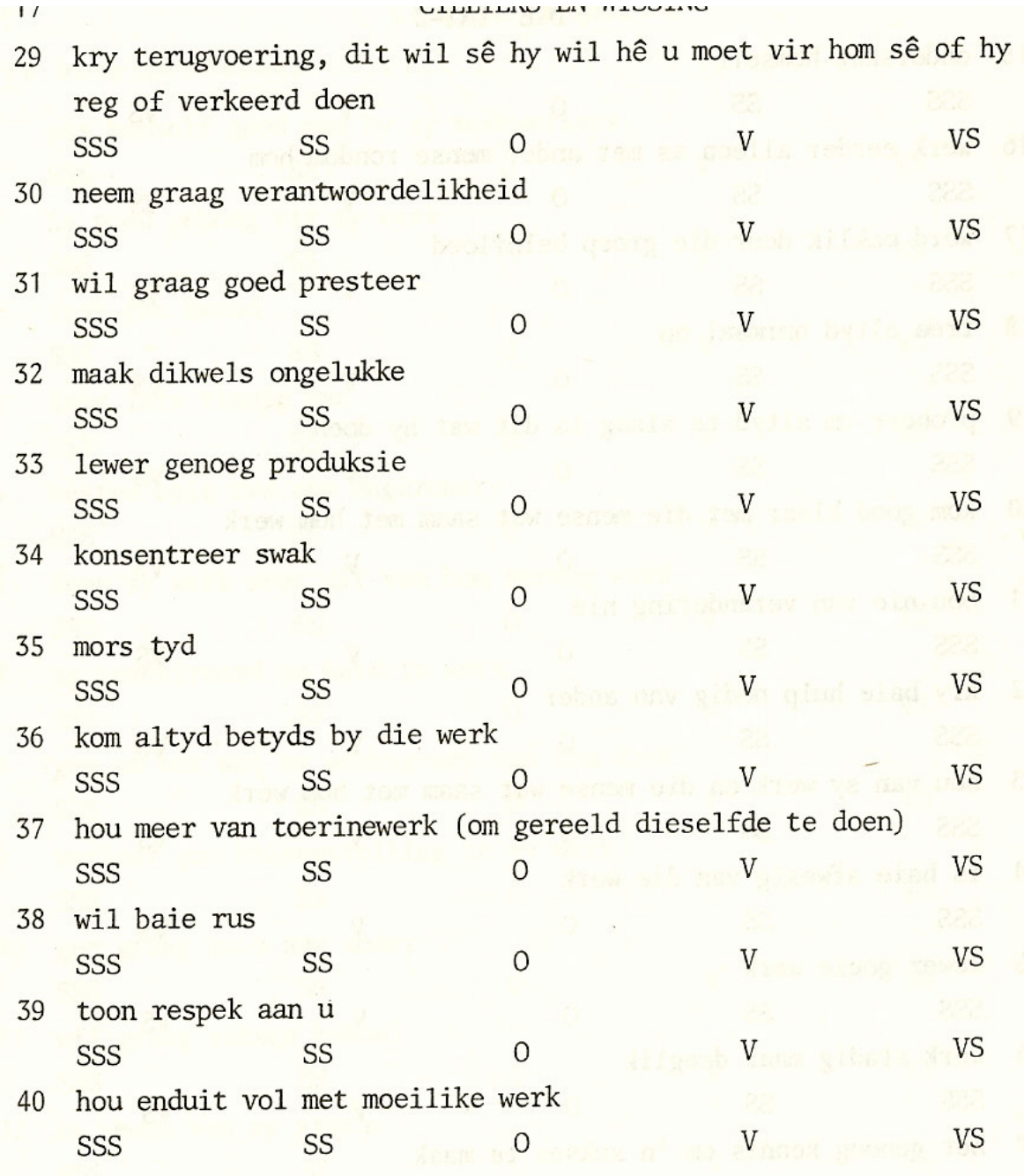

Wat die meting van realiteitsbelewing en verwestering deur middel van die TAT-Z betref is die resultate minder bemoedigend en verdere navorsing behoort hierop gedoen te word.

\section{OPSOMMING}

Die gebruik van die TAT-Z, 'n projeksietoets vir Swartmans, word ondersoek om prestasiemotivering veral tydens die indiensnemingsituasie te voorspel. Positiewe resultate is op 3 van die 10 kaarte (nrs. 4, 6 en 9) van die TAT-Z verkry. Aanbevelings word gemaak aangaande die aanpassing van hierdie projeksietoets ten einde meer inligting oor prestasiemotivering, bloot te lê. 


\section{VERWYSINGS}

Atkinson, J.W. en Feather, N.T. A Theory of Achievement Motivation. New York: 1966.

Barnard, A.L. ' $n$ Vergelykende Ondersoek van Motiveringsfaktore in Enkele

Beroepskategorië̈. Doktorale proefskrif, Universiteit van die Oranje-Vrystaat, Bloemfontein, 1971.

Coertze, C.J. 'n Evaluasie van die Verband tussen die Prestasiemotief en Merietebepaling. Magisterverhandeling, Universiteit van Pretoria, Pretoria, 1974.

Costello, C.G. Two scales to measure achievement motivation. Journal of Psychology, 1967, 66, 231.

Erasmus, P.F. Die Persoonlikheid van die Suid-Afrikaanse Bantoe aan die Hand van die Analitiese Sielkunde van Szondi. Doktorale proefskrif, Potchefstroomse Universiteit vir C.H.O., Potchefstroom, 1971.

Fullard, J.P.P. 'n Ondersoek na die Biografiese Eienskappe van Studente met Hoë en Lae Prestasiemotivering. Magisterverhandeling, Universiteit van Port Elizabeth, Port Elizabeth, 1969.

Heckhausen, H. The Anatomy of Achievement Motivation. New York: Academic Press, 1957. Hermans, H. Motivatie en Prestatie. Amsterdam: Swets en Zeitlinger, 1967.

Johada, M. en Warren, N. Attitudes - Selected Readings. Penquin Books, 1966

McClelland, D.C. Achievement motive and motivation for economic achievement. People and Profits. 1977, 5(1).

McClelland, D.C. The Achieving Society. New York: Free Press, 1961.

McClelland, D.C. en Winter, D.G. Motivating Economic Achievement. New York: Free Press, 1969.

Minnaar, G.G. Die Invloed van Verwestering op die Persoonlikheid van 'n Groep Zoeloemans. Doktoraleproefskrif, Universiteit van Pretoria, Pretoria, 1975.

Oppenheim, A.N. Questionnaire Design and Attitude Measurement. London: Heineman, 1968.

Orpen, C. Productivity of Black Workers in South Africa. Kaapstad: Juta, 1976.

Pottas, C.D. ' $n$ Bedryfsielkundige Ondersoek na die Determinante van Werksverhoudinge en Werksmotivering. Magisterverhandeling, Universiteit van Suid-Afrika, Pretoria, 1969.

Rim, Y. Risk taking and need for achievement. Acta Psychologica, 1963, 21, 109.

Sherwood, J.J. Self-report and projective measures of achievement and affiliation. Journal of Counseling Psychology, 1963, 30, 329.

Van der Merwe, W.G. Die Persoonlikheid van Suksesvolle Xhosa Sakemanne met Spesiale Verwysing na Prestasiemotivering. Doktorale proefskrif, Universiteit van Suid-Afrika, Pretoria, 1976.

Weiner, B. Achievement Motivation and Attribution Theory. Morristown, New Jersey: General Learning Press, 1974. 